\title{
perifèria
}

Número 6, Julio 2007

www.periferia.name

\section{Universalismos / relativismos y antropología: una aproximación al debate}

\author{
Óscar López Catalán - Universitat Autònoma de Barcelona ${ }^{1}$
}

\section{Resumen}

Este artículo pretende una aproximación inicial al debate universalismo/relativismo en Antropología, en el que se intentan sistematizar algunas de las críticas y contracríticas que se han articulado en la discusión. Sin embargo, más que de una revisión histórica, se ha intentado desarrollar una postura "relativista radical" y contraponerla con diferentes aportaciones, con la intención de explorar algunas de las implicaciones del debate para la práctica antropológica.

Palabras clave: epistemología, universalismo, relativismo cultural.

\section{Abstract}

This paper is intended to be an initial approach to the universalism / relativism debate in Anthropology, trying to systematize some of the critics and counter-critics that have been used in that discussion. However, more than an historical review, it tries to expound a "radical relativist" position and confront it with different contributions, with the objective of exploring some of the implications of the debate for anthropological practice.

Keywords: epistemology, universalism, cultural relativism.

\section{I ntroducción}

El objetivo de este texto no es hacer un recorrido histórico por el debate entre posturas universalistas y relativistas en Antropología, ni siquiera el de resumir unas y otras, sino una aproximación a algunos de sus efectos y consecuencias sobre la construcción de conocimiento en ciencias sociales. Si bien intentaré plantear ciertas cuestiones que aparecen con bastante frecuencia en diferentes ámbitos (no todos disciplinares), cuando nos interrogamos sobre las implicaciones de nuestra práctica como antropólogos, sería difícil hacer una aproximación al mismo que pretendiera

\footnotetext{
1 Becario FPU-MEC. Departament d'Antropologia Social i Cultural (UAB). Enviar correspondencia a: oscarlcat@gmail.com
} 


\section{perifèria}

Número 6, Julio 2007

www.periferia. name

basarse en una presentación supuestamente "neutra" de las diferentes posiciones y de la forma en que hayan podido ir modificándose con el tiempo. Además, resumir o presentar la mayoría de aportaciones a una discusión que lleva planteada, de una u otra manera, desde los orígenes de las ciencias sociales, se escapa a los objetivos de este texto y a mi propia capacidad: por tanto, probablemente los argumentos y reflexiones se mezclen, confundan y repitan; y sin duda, en ocasiones, he simplificado en exceso y me he alejado de los objetivos iniciales. Siendo coherente con todo ello, el artículo debe ser entendido como un primer ejercicio de reflexión a partir de una toma de postura por mi parte, necesaria y a la vez necesariamente explícita, a partir de un enfoque que he considerado interesante analizar y poner en relación con otras aportaciones, para después intentar extraer ciertas conclusiones o vías de entrada (nuevos interrogantes, en definitiva) sobre la discusión. El grueso de dicho enfoque, que se ha dado en llamar "relativismo radical"2, ha sido tomado del texto "Municiones para disidentes" (2001) de Tomás I bañez. De entre los otros textos que voy a utilizar, tienen especial importancia dos: el titulado “Tesis epistemológicas. Las paradojas del relativismo" (2003:400-416), perteneciente al libro Crítica de la Singularidad cultural, de Aurora González Echevarría y el artículo "Los hacedores de mapas: antropología y epistemología" (1991), de Rodrigo Díaz Cruz.

Entre esta introducción y aquellas conclusiones, intentaré presentar lo más ordenadamente posible un debate que por definición es complejo y polifacético, dividiendo el artículo en dos apartados. El primero, "Una aproximación inicial a los universalismos y relativismos" intenta dejar claras algunas cuestiones básicas en cuanto a los conceptos que incorpora el texto: tras situar brevemente los inicios del debate, abordo en primer lugar la cuestión del realismo, para después, teniéndolo en cuenta, intentar caracterizar diferentes tipos de universalismos y relativismos. El segundo apartado, titulado "Relativismo versus Absolutismo" es el que contiene el grueso de aportaciones del texto de I báñez. Me ha parecido interesante revisarlo y resumir las críticas y contra-críticas que el autor pone en juego al explicar el

\footnotetext{
2 También "relativismo fuerte" o "strong relativism" (Foster, 1988).
} 


\section{perifèria}

Número 6, Julio 2007

www.periferia.name

debate, manejando además otros textos que recogen aportaciones de diferentes autores en antropología que entran en relación con las críticas al relativismo radical. , Debo advertir que sólo he rozado la superficie de dichos trabajos, y que la selección bibliográfica sin duda podría ser mucho más amplia. Pero eso queda emplazado para un futuro, pues necesita de un tiempo ( $y$ un espacio) del que carezco.

Debo hacer mínimamente explícito el porqué de la elección del texto de I bañez El primer motivo viene del aura de desconfianza/temor/rechazo (depende del caso) que, en ocasiones, envuelve el uso de una cierta concepción del relativismo en textos, debates y foros varios; mi interés viene, por tanto, del cuestionamiento de los porqués a esta situación. El segundo es sondear las implicaciones que ciertas posturas tienen para algunos de los interrogantes que rodean la práctica antropológica. Para dar cuenta de unos y otras, he creído interesante contrastar los argumentos - contraponer visiones- para después tratar, en el último apartado, de apuntar algunas conclusiones. Estas últimas se aproximan más, necesariamente, a herramientas para la reflexión que a puntos finales al debate. $Y$, probablemente, esto tiene también mucho que ver con la cuestión que trato de abordar: aun admitiendo que, a veces, nuestras posiciones no están lo suficientemente claras y/o fundamentadas, el debate es inevitable e imprescindible, ya que sus implicaciones se vuelven tangibles cuando se trata de poner en práctica la antropología. Quizás, como afirma Geertz, sólo por eso ya merece la pena tratar de abordarlo:

(...) difícilmente un investigador utilizará mejor sus capacidades que cuando destruya miedos. (...) Las consecuencias morales e intelectuales que comúnmente se supone derivan del relativismo -exclusivismo ético, subjetivismo, nihilismo, incoherencia, maquiavelismo, ceguera estética etc.no son en realidad tales (son otras). $Y$ las recompensas prometidas para quien escape de sus garras, y que tienen que ver más con una concepción pasteurizada del conocimiento, son ilusorias. (1984:263, citado en Díaz, 1991:6)

\section{Una aproximación inicial a los universalismos / relativismos}

No se puede plantear el debate partiendo de una dicotomía polarizada y exclusiva, que fuera de lo que podríamos denominar un "universalismo absoluto" a un "relativismo radical", sino de un continuum de posiciones que varían en función de 


\section{perifèria}

Número 6, Julio 2007

www. periferia. name

los temas en los que sitúa la postura. Es necesario apuntarlo aquí para entender que el debate no siempre se ha desarrollado de una forma totalmente transparente, con ataques y defensas claras por parte de las dos supuestas partes. Por otra parte, es difícil situar un punto de partida para dicho debate, o situar sus orígenes en un ámbito disciplinar concreto dado que, como veremos más adelante, tampoco estamos hablando de un solo tipo de universalismo o relativismo. Como afirma González Echevarría (2003:405), para el relativismo cognoscitivo, éste "vino primero de la filosofía de la ciencia, después de su historia y de su sociología. La historicidad de las propuestas de método científico, la imposibilidad de establecer un criterio de demarcación entre ciencia y conocimiento no científico y las tesis sobre la incomparabilidad de las teorías científicas fueron el punto de partida". EI debate entre "universalismos" y "relativismos" no se circunscribe, por tanto, a las ciencias sociales, a pesar de que éstas, y en concreto la antropología, no han permanecido ajenas a él. Es una disputa, tal y como mantiene Díaz (1991:3) que "también ha estado presente en otras disciplinas claramente demarcadoras ${ }^{3}$ como la historia, la filosofía de la ciencia y la sociología del conocimiento [y que] ha circulado, ora profusa, ora tímidamente, por una buena parte de las ciencias sociales desde el siglo pasado". De hecho, el debate entre el relativismo moral y el universalismo parece venir de mucho más atrás, cubriendo una parte considerable de la reflexión filosófica en ética. En la Grecia antigua, al menos algunos de los «sofistas» defendieron una versión del relativismo moral que Platón intentó refutar. Platón atribuye al primer gran sofista, Protágoras, el argumento de que la costumbre humana determina lo hermoso y lo feo, lo justo y lo injusto. Según este argumento, en realidad es válido aquello que colectivamente se considera válido. Sin embargo, no está claro si Protágoras argumentó realmente de este modo. Más adelante retomaré esta cuestión.

\footnotetext{
${ }^{3}$ Díaz (1991:3) caracteriza la antropología como una disciplina a la que le "conciernen las fronteras, los linderos, las demarcaciones" (entre culturas, entre naturaleza y cultura, entre diferentes tipos de pensamiento, etc.)
} 


\section{perifèria}

Número 6, Julio 2007

www.periferia.name

Lo que me interesa destacar aquí es, coincidiendo con Bernstein (1983:8, citado en Díaz, 1991:3), la importancia de este debate, "no solo por las implicaciones epistémicas que supone, sino también por sus consecuencias políticas y éticas". Los conflictos entre relativismo y universalismo (como el que Platón iniciaba en el párrafo anterior) tampoco se han dado exclusivamente dentro de la discusión académica. El nuevo Papa de la iglesia católica, Benedicto XVI, en su última homilía como cardenal Ratzinger alertó contra los peligros del relativismo, de la misma forma en que Juan Pablo II, en 1993, lo hizo a través de su encíclica "veritatis esplendor". En la misma línea, diversos cardenales de la Conferencia Episcopal española vienen denunciando, en los últimos meses, la "dictadura del relativismo" (ético o moral, dependiendo del caso), como el "máximo peligro para el futuro del estado democrático de derecho"4 ${ }^{4}$. Algunos de los posicionamientos del relativismo cultural han sido simplificados y aprovechados por ciertos movimientos para justificar discursos y acciones xenófobos y, por otra parte, han empapado discursos socialmente muy extendidos que culturalizan procesos de exclusión social y colectivos afectados por ellos. Algunos relativistas acusan a los universalistas de dogmáticos y positivistas, y estos les responden acusándolos de su falta de rigurosidad, ética y compromiso. Ciertos relativismos pueden estar identificados con el antiautoritarismo, mientras otros lo hacen con el neoliberalismo. De la misma forma, un universalista podría autodefinirse como anarquista, marxista, fascista o cualquier otra cosa.

La cuestión es muy compleja, y quizás no es adecuado atribuir etiquetas genéricas de una forma dicotómica. Si afirmamos, como hace Todorov (1988:6) que "la ideología nazi fue violenta y sistemáticamente anti-universalista", habría, en todo caso, que observar respecto a qué: porque quizás lo fue respecto a la unidad de toda la humanidad, pero probablemente no respecto a lo universal de su discurso

\footnotetext{
${ }^{4}$ Del discurso de investidura del cardenal Rouco Varela como Doctor Honoris Causa por la Universidad San Pablo CEU (2006). Sirva también como ejemplo el siguiente fragmento de un texto del Cardenal Cañizares Llovera (2007): “Estamos inmersos [...] en un puro relativismo que carcome y destruye la sociedad. Por ahí no hay salida, ni progreso. El relativismo es destructor, y ni el hombre, ni la sociedad tienen futuro si lo siguen. Tampoco la democracia puede asentarse sobre el relativismo, que no tiene base alguna. El relativismo lleva la destrucción de la democracia y genera violencia y totalitarismo: el de la dictadura del mismo relativismo."
} 


\section{perifèria}

Número 6, Julio 2007

www.periferia. name

de superioridad racial, o a la propia existencia de razas. Cabe hacer, por tanto, una precisión añadida: cuando se adjudican etiquetas hace falta también contextualizarlas, porque éstas dependen de la problemática concreta, del "objeto" de discusión o investigación, de los efectos de los conceptos utilizados, y, por supuesto, del propio emisor (su trayectoria, experiencia, posicionamientos teóricos, políticos, etc.). Los ejemplos pueden, en consecuencia, ser muy variados, y para analizarlos es preciso conocer al menos una de las discusiones que subyacen al debate entre relativismos y universalismos, la relacionada con la realidad.

\section{El debate sobre la realidad}

El debate sobre la realidad está en el fondo de muchas de las polémicas en torno a la oposición universalismos / relativismos, y aborda aspectos tan básicos como los de la existencia de una realidad objetiva y nuestra posibilidad de acceso a ella. En este sentido cabe distinguir, siguiendo a Ibáñez (2001:19), dos posturas básicas. El realismo ontológico afirma que la Realidad existe y que lo hace con independencia de nosotros. Sus características son las que son, las observemos o no, las conozcamos o no, tanto si existimos nosotros mismos como si no. Por su parte, el realismo epistemológico afirma que podemos conocer dicha Realidad. Esta supuesta obviedad implica algo que está en la base de la idea de ciencia que comúnmente manejamos: que el conocimiento es válido, precisamente, en la medida en que constituye una forma de acceso a la realidad tal como es.

Definidos de ese modo, el segundo (realismo epistemológico), implica al primero, ya que es imposible constituir vías de acceso a la realidad si ésta no existe. Sin embargo, no siempre se puede hacer el recorrido inverso: el realismo ontológico (la realidad existe con independencia de nuestro acceso a ella), no implica necesariamente el realismo epistemológico. De hecho, una gran parte de las concepciones científicas han "abandonado" (explícita o implícitamente) este último, pero manteniendo el primero. Para ello se han sustituido palabras como "objetividad" por términos como "intersubjetividad", asumiendo la dificultad de una aproximación que inevitablemente se modifica con nuestro acceso al "objeto". Esto es muy patente en ciencias sociales, pero sus formulaciones más claras no siempre 


\section{perifèria}

Número 6, Julio 2007

www.periferia. name

han venido de ellas: una crítica fundamental al realismo epistemológico -y al objetivismo- viene, entre otros, de Richard Rorty (1996, citado en Ibáñez, 2001:20) y parece tener, a primera vista, un efecto tan demoledor como simple. En pocas palabras, vendría a afirmar que no existe una vía de acceso a la Realidad que no pase por nuestro "conocimiento de la realidad". ¿Cómo podemos, por tanto, comparar nuestro "conocimiento de la realidad" con la "Realidad-en-sí" y ver cómo de cercanas son? Si no es posible, ¿cómo establecer una jerarquía entre diferentes "conocimientos de la realidad" en función de la calidad de su aproximación a la misma? Este argumento no resuelve, evidentemente, el debate, pero contribuye, entre otros, a debilitar o desarticular el realismo (fundamentalmente el epistemológico).

\section{Universalismos y relativismos}

Cuando se habla de universalismo y de relativismo, ¿qué queremos decir exactamente? ¿Existe un solo tipo de universalismo y relativismo? ¿Cómo caracterizarlos? ¿Qué relación tiene el término "absolutismo" con el de "universalismo"? Siguiendo la postura de Ibáñez (2001: 64) el absolutismo se articula por lo menos en torno a uno de entre tres supuestos: el universalismo, que afirma que existen características epistemológicas, ontológicas, axiológicas, etc. que son a-temporales, a-tópicas, no contextuales, es decir, que sirven para todos los lugares, momentos y en todos los contextos; el objetivismo, que afirma que existen conocimientos, creencias, valores o existencias que son independientes de cualquier punto de vista particular; y el fundacionalismo, por último, que afirma que existen unas bases últimas, irreductibles a niveles más elementales, sobre las que se asienta todo lo que se puede legítimamente afirmar, o todo lo que puede existir. Lo lógico es, entonces, presentar el debate en el apartado siguiente en términos de "absolutismos" versus "relativismos", ya que, aunque el "universalismo" puede ser el más visible de los tres supuestos presentados más arriba, los otros dos se encuentran, en muchas ocasiones, implícitos (y no tan 


\section{perifèria}

Número 6, Julio 2007

www. periferia. name

implícitos) en planteamientos teóricos que incluyen el primero ${ }^{5}$. Aunque, al menos en antropología, un cierto relativismo ha estado muy extendido, a lo largo del debate han sido los universalismos los que generalmente han aparecido como dominantes en la tradición occidental. En consecuencia, el relativismo ha surgido en ocasiones como una respuesta crítica con estos planteamientos. Dada su multiplicidad de ambos, ¿cómo caracterizarlo? Siguiendo a I báñez, cuando se habla de relativismo, habría que precisar al menos tres cosas:

En primer lugar, ¿Qué es aquello que se relativiza? (el conocimiento, los valores, las culturas, la realidad, etc.). En segundo lugar, ¿respecto a qué se relativiza lo relativizado? (al lenguaje, a los esquemas conceptuales, a las teorías, etc.). Por fin, ¿en que grado se relativiza lo relativizado? (en su totalidad, parcialmente, etc.). (2001:63)

O, como mantiene Spiro (1984), matizando a Boas (citado en González Echevarría, 2003: 402), referente al relativismo cultural: “Relativismo cultural podría significar que la cultura es relativa a algo, que algo es relativo a la cultura o que las partes de la cultura están interrelacionadas." Siguiendo con González Echevarría, el relativismo cultural de Boas (al menos en su tesis ideológica / particularista) parecería referirse a lo último, es decir, a que las partes de la cultura son relativas a la cultura de la que forman parte: en otras palabras, aunque sea redundante, un relativismo cultural de los elementos culturales. Aunque en este caso está perfectamente claro, frecuentemente, en otros textos, se habla indiscriminadamente de diferentes relativismos o universalismos (o de relativismo o universalismo globalmente), poniendo todo el acento en la primera pregunta (qué se relativiza), un poco menos en la tercera (en qué grado) y llegando a obviar la segunda (respecto a qué). En general, se puede asumir que cuando es así (cuando se menciona qué pero no respecto a qué), estamos hablando de un relativismo respecto a factores socioculturales, aunque lo cierto es que esta práctica puede inducir con facilidad a confusiones ${ }^{6}$. Entonces, y retomando esa pregunta,

\footnotetext{
${ }^{5}$ Díaz (1991:3) prefiere, por ejemplo, referirse al debate entre "objetivismo" y "relativismo".

${ }^{6}$ Díaz (1991:6), por ejemplo, propone que "en antropología ha existido la tendencia a reducir todo el relativismo al relativismo ingenuo de la antropología culturalista norteamericana [en un] vértigo reduccionista" lo cual ha obstaculizado tanto el análisis de los problemas que planteó, como de los conceptos derivados de dichas propuestas.
} 


\section{perifèria}

Número 6, Julio 2007

www.periferia.name

podríamos diferenciar (a pesar de la inevitable dificultad para caracterizarlos ${ }^{7}$ ) múltiples tipos de relativismo, por ejemplo: el moral/ético/axiológico, el de verdad/de razón; que voy a tratar, a modo de ejemplo, de caracterizar.

El relativismo moral suele asumir la forma de negación de que exista un único código moral con validez universal, y se expresa como la tesis de que la verdad moral y la justificabilidad -si existen cosas semejantes- son en cierto modo relativas a factores cultural e históricamente contingentes. En ese sentido, un relativismo ético, tomado de una forma estricta, afirmaría que es erróneo juzgar valores sustancialmente diferentes, o intentar que se adecuen a los nuestros, en razón de que dichos valores son tan válidos como los propios. El relativismo de verdad y el de razón tienen que ver con el debate sobre la realidad del que hablé más arriba. Enn pocas palabras, el primero afirmaría que no existe una verdad, sino diferentes maneras de afrontar la experiencia cotidiana. El relativismo de razón atacaría la idea de la existencia de una sola razón (en el sentido ilustrado) en tanto que esto establecería una jerarquización que podría suponer que otras tradiciones son "inferiores" en cuanto a su racionalidad.

Como apuntaba antes, el relativismo cultural es, probablemente, el que más frecuente y directamente se ha relacionado con la antropología, fundamentalmente desde la corriente culturalista norteamericana de principios del siglo XX. A grandes rasgos, viene a decir que diferentes grupos obtienen su experiencia a partir de diferentes contextos. $\mathrm{O}$, en otras palabras, que dicha experiencia del mundo está mediatizada por diferentes modelos culturales. Como plantea Díaz (1991:4), dicho relativismo surgió "como reacción al evolucionismo social, de carácter universalista [y] desde su emergencia encontró severos críticos, sobre todo en la antropología británica". En todo caso, y siguiendo con la caracterización, ciertas premisas del relativismo cultural derivan también en un relativismo conceptual: los conceptos manejados por cada cultura son productos socio-históricos y culturales. La

\footnotetext{
7 Me remito aquí algunos de los tipos que propone González Echevarría (2003), pero sólo enumerándolos. Para una explicación completa y una argumentación de dichas dificultades, ver: González Echevarría (2003:400-406 y ss.)
} 


\section{perifèria}

Número 6, Julio 2007

www. periferia. name

aceptación de la imposibilidad de una aproximación puramente objetiva tiene bastante que ver en ello. En principio cualquier orientación de cierto corte universalista estaría completamente de acuerdo con esto, pero tendería a buscar las lógicas subyacentes, situando las diferencias en las manifestaciones concretas de un elemento común. El límite, no viable ya en antropología, estaría en afirmar la inconmensurabilidad, es decir, en mantener que el orden del mundo solo tiene sentido en sí mismo, desde dentro de la propia cultura. En tanto que los diferentes grupos vivirían en diferentes mundos que no se podrían entender y aprehender mutuamente, el lenguaje, las pautas culturales, las cosmovisiones, además de incorporarse inconscientemente acabarían constituyendo experiencias únicas del mundo, sin posibilidad de una comunicación entre ellas. ¿Cuál sería entonces el objeto de la Antropología (basada necesariamente en la comparación)? ¿Dejaría de ser posible? Ésta es una de las críticas fundamentales de las tendencias de corte más universalista al relativismo cultural antes mencionado, pero no es la única que, en general, se ha utilizado contra el relativismo.

\section{Relativismo frente a absolutismo: un intento de sistematizar críticas y contacríticas}

A lo largo del texto, I báñez va argumentando acerca de diferentes críticas que, desde los "absolutismos" se utilizan para desarticular el discurso relativista. Pero también carga contra las posturas relativistas que, según él, siguen apoyando, en el fondo, concepciones "absolutistas". Siguiendo la argumentación de Tomás I báñez y apoyándome en unos pocos autores de Antropología, vemos que algunas de las críticas - como las de Gellner (1982)- pueden situarse en casi todos los apartados. Con esto no quiero decir que no existan autores en Antropología que tengan amplios puntos de coincidencia con el llamado "relativismo radical", sino simplemente que me ha interesado más contraponer las posiciones de aquellos que se han mostrado más beligerantes con algunos o todos de los elementos de dicho relativismo tal y como lo interpreta Ibáñez (2001:64): un relativismo que lo relativiza todo (incluso a sí mismo), y que rechaza en bloque los tres supuestos básicos del absolutismo. Para éste, por tanto, no serían propiamente relativistas ni el perspectivismo (un cierto relativismo epistemológico), que afirmaría la existencia 


\section{perifèria}

Número 6, Julio 2007

www. periferia. name

de varias visiones posibles de un mismo mundo, ni tampoco el pluralismo (el admitir que existe una pluralidad de culturas, de lenguas, etc.) .

\section{Crítica 1. Entonces, ¿este artículo no existe?}

Si el relativismo radical niega las tres formas de absolutismo, está negando también el realismo ontológico, por lo que parece necesario retomar aquí la cuestión. Ante el debate anterior, generalmente, se han admitido dos resultados: o bien se mantiene que el debate queda en tablas (es imposible saber quien tiene la razón) o bien se propone un relativismo moderado, que admita la subjetividad, pero deje intacto el objeto (Ibañez, 2001:63). Algunos convendrían en que el criticar la existencia una realidad independiente de nuestro acercamiento a ella es, bien una locura, bien un delirio de complejos razonamientos filosóficos. Sin embargo, es bueno recordar que para algunas disciplinas como la física cuántica, tanto el realismo epistemológico como el ontológico resultan inviables para ciertos supuestos y situaciones. No voy a desarrollar aquí dichos supuestos (pueden leerse en Ibáñez, 2001:17-50), pero sí me gustaría comentar un argumento que gira en torno a la misma cuestión y que se suele utilizar en los debates (quizás por ser más “tangible") para justificar una postura "objetivista", frente a la crítica a la realidad ontológica. Denominado "el golpe sobre la mesa", dicho argumento consiste en introducir en la discusión un objeto "indiscutiblemente" real (como podría ser este artículo ${ }^{8}$ ), con la pretensión de mostrar lo absolutamente "real" de su existencia. ¿Cómo negar que la mesa / el artículo (o las leyes de la física ${ }^{9}$ ) tienen una existencia "real" independiente de nuestra aproximación a los mismos?

Una posible argumentación (si tomamos como ejemplo este artículo) puede girar, entonces, en torno a varias cuestiones: La primera es que este artículo es un artículo "en tanto que" existe una idea compartida de lo que es un artículo científico, un texto, etc. Tampoco es posible definir cuantos objetos "existen" sin

\footnotetext{
${ }^{8}$ A pesar de encontrarse en un ámbito "virtual"

9 Una versión más elaborada (y cáustica) del "golpe sobre la mesa" es la mantenida por Sokal (1996a:2): "Cualquiera que crea que las leyes físicas son meras convenciones sociales, está invitado a que pruebe a transgredir dichas convenciones desde la ventana de mi apartamento (vivo en un piso 21)".
} 


\section{perifèria}

Número 6, Julio 2007

www. periferia. name

una interpretación derivada de nuestra propia idea de "objeto": el artículo puede ser considerado como tal, pero también lo pueden ser sus páginas, sus palabras, sus letras, etc. Simplificando mucho la argumentación, el resultado es que la variabilidad de versiones y niveles puede resultar infinita. Y la lógica respuesta desde "el golpe sobre la mesa" podría ser, tomando un conocido diálogo sobre las estrellas: "Podemos seguir así hasta que usted se canse, pero lo que me resulta claro es que lo único que consigue demostrar, es que sin versiones del mundo las estrellas no existirían en "tanto que estrellas", pero, desde luego, existirían estrellas" (Goodman, 1990; citado en Ibáñez, 2001:83). Es decir, aceptación de de la subjetividad en el acceso a la Realidad ${ }^{10}$ (no podemos saber si nuestra versión de estrellas es realmente verdadera), pero mantenimiento de una Realidad externa a nuestro propio acceso a ella. La respuesta con la que continúa el diálogo anterior sirve para seguir argumentando la crítica al realismo ontológico:

$\mathrm{R}$ : Si usted quiere, pero, estrellas que no son, en "tanto que estrellas", estrellas que no son "en tanto que algo que se mueve" o "en tanto que algo que brilla", elementos, objetos que no son "en tanto que algo", resulta que no son nada. Si usted se está refiriendo a la existencia de algo, lo llame como lo quiera llamar, o bien lo hace desde una determinada "versión del mundo" o bien es como si no se estuviera refiriendo a nada.

Tratando de resumir a Goodman, lo que está en juego aquí no es la cuestión del "ser" de algo, sino la cuestión de su "existencia". En otras palabras, no se niega que este artículo "sea", sino que no tiene un "modo de ser" verdadero, una determinada forma de "existir" independiente de nuestro punto de vista. No es "real" porque el sentido del término realidad implica una modalidad de existencia, con ciertas propiedades, determinadas y susceptibles de ser descubiertas. Estaríamos, por tanto, no sólo ante una crítica a un cierto "logocentrismo", concepto que, tal como afirma González Echevarría (2003:459), fue propuesto inicialmente por Derrida para "referirse al supuesto de que las palabras se refieren

10 A lo largo del texto, siguiendo a Ibañez, utilizo "Realidad" (con mayúsculas) para referirme a la realidad externa, objetiva. Lo mismo es aplicable al término "Verdad". 


\section{perifèria}

Número 6, Julio 2007

www. periferia. name

directamente y de manera no problemática a cosas externas"11; sino también al propio establecimiento acrítico de propiedades, valores, e ideas sobre dicha "realidad externa".

Las implicaciones de este razonamiento para las ciencias sociales y la Antropología son, evidentemente, enormes. Si aceptamos que posibles objetos de la Antropología (una sociedad, comunidad, cultura o ámbito determinado) "son" (indudablemente), pero no "existen" (en los términos que estamos utilizando) es necesario renunciar a la posibilidad de construir conocimiento objetivo y verdadero (en el sentido de su aproximación a la "realidad-en-si" de dichos objetos de estudio). Tomando una cita de Díaz (1991:4), a la cual quizás habría que restar los adverbios "sólo" y "también": "el otro no sólo es un sujeto que está ahí, en espera de ser revelado y evangelizado, descubierto y civilizado, es también aquello que los diversos discursos de la alteridad han delimitado y producido bajo ciertas condiciones de inteligibilidad y emergencia". En otras palabras, al hacer Antropología no podemos pretender estar desentrañando una única versión de la realidad (la que realmente "existe", de una forma oculta o subyacente) sino estar construyendo conocimiento desde una multiplicidad de versiones del "ser" de dichos objetos. Y lo que es aun más importante: admitir que nuestro objeto de estudio "existe" de una determinada manera en tanto que "nuestro objeto de estudio" nos obliga a ser conscientes constantemente de su carácter construido y, por tanto, de nuestra responsabilidad a la hora de construir conocimiento sobre él. Lo mismo puede ser extensible a los conceptos que utilizamos, lo que hace aun más imprescindible una operacionalización clara de los mismos. En otras palabras, y por expresarlo con claridad, el carácter construido de los conceptos que utilizamos y del conocimiento sobre nuestros objetos de estudio no puede, de ninguna manera, servir de excusa para, simplemente, abandonarlos. Si acaso debe ser un acicate para ser más críticos y exigentes con ellos -y sus consecuencias- porque, al fin y al

\footnotetext{
11 Morrow y Brown (1994:234, citado en González Echevarría, 2003:459) lo definen como “a foundationalist conception of truth that denies the signifiance of the linguistic baiss of all forms of representation".
} 


\section{perifèria}

Número 6, Julio 2007

www.periferia.name

cabo, y como se afirma en la siguiente cita (me permito un pequeño excurso) es "todo lo que tenemos y todo lo que podemos tener":

Querido Pel - Dijo Bliss -[...]. La cuestión es: ¿Qué sentirías al hacer el amor a un robot?

El la miró, inquieto.

- ¿Un robot realmente indistinguible? ¿Un robot que no se puede diferenciar de un ser humano? [...] Me parece que un robot, indistinguible de un ser humano, es un ser humano. Si tú fueras un robot de esa clase, sólo serías un ser humano para mí.

- Eso es lo que deseaba oírte decir, Pel.[...]

- Entonces, ya que lo he dicho, [...] ¿no vas tú a decirme que eres un ser humano natural y que no necesito considerar situaciones hipotéticas?

- No haré tal cosa. Tú has definido el ser humano como un objeto que tiene todas las propiedades de un ser humano. Si estás convencido de que yo tengo todas esas propiedades, entonces, la discusión acabó. Tenemos la definición operacional y huelga todo lo demás. A fin de cuentas, ¿cómo puedo yo saber que tú no eres más que un robot indistinguible de un ser humano?

- Porque yo te digo que no lo soy.

- ¡Ah! Pero si fueses un robot indistinguible de un ser humano, podrías haber sido diseñado para decirme que eres un ser humano, o incluso haber sido programado para que tú mismo lo creyeras. La definición operacional es lo único que tenemos, y todo lo que podemos tener.

Rodeó el cuello de Pelorat con los brazos y lo besó. (Asimos, 2003:63)

\section{Crítica 2. La realidad y la Realidad}

La primera crítica lleva directamente a esta segunda, que critica las repercusiones prácticas de la negación del realismo ontológico, intentando demostrar lo "autocontradictorio" del relativismo a partir de la contradicción en que incurre el relativista al recurrir en la práctica a aquello mismo que renuncia en la teoría, es decir, a la verdad y a la realidad. Un ejemplo, desde el uso del lenguaje, es el que apunta Díaz (1991:11) cuando dice: “al señalar que es equivocado para la gente de una sociedad condenar o interferir en los valores y conducta de otra [...] utiliza el término "equivocado" en un sentido no-relativo". ¿Cómo puede mantenerse una postura de negación del realismo ontológico y, al mismo tiempo, actuar en nuestras prácticas cotidianas siguiendo - inevitablemente- ciertas "coordenadas de realidad"? ¿No convierte esta divergencia el discurso relativista en algo impracticable? Desde el relativismo radical la respuesta es que no se niegan los conceptos de realidad y verdad, en su uso cotidiano y relacional, sino la "resignificación" que de ellos ha 


\section{perifèria}

Número 6, Julio 2007

www. periferia. name

hecho la filosofía occidental, colocándolas fuera de lo humano, de lo cotidiano. En otras palabras, para el concepto de verdad:

El relativista no renuncia al concepto de verdad, pero considera que la verdad es siempre relativa a unas determinadas "condiciones de verdad", propias de un determinado contexto de enunciación, [...] que se articulan siempre sobre la base de un conjunto de decisiones, implícitas o explícitas, pero que no son por ello arbitrarias. Nuestras convenciones se encuentran constreñidas por el tipo de resultado que pretendemos conseguir con ellas, o por el tipo de práctica que pretendemos llevar a cabo, o por el tipo de relaciones que pretendemos habilitar. (I báñez, 2001:67)

Lo mismo ocurriría con la realidad, y si se quiere, con el lenguaje: criticar una Realidad objetiva y externa, por ejemplo, respecto a ciertos aspectos de la salud no implica que, arbitrariamente, considere que consumir veneno puede ser malo o bueno para mí; y considerar que el término "equivocado" no tiene un significado absoluto y válido en todos los contextos no impide para nada que pueda utilizarlo para comunicarme cotidianamente. De alguna manera, el relativismo devolvería la capacidad de hacer verdades (con minúscula) al plano de lo humano, de lo cotidiano. $Y$ uno de sus posibles efectos es el impedir amparar el conocimiento en puntos externos a este plano, empujando, por tanto, a la argumentación, a la necesidad de clarificar las condiciones y el contexto de enunciación de dichas verdades, realidades o lenguajes. Hablaré de ello más adelante, pero esta posición iría en la línea de Feyerabend (1974), cuando afirma que el conocimiento científico jugó en principio un papel "liberador" frente a tradiciones que colocaban sus principios argumentativos en, por ejemplo, un Dios, para después convertirse en un nuevo elemento con un papel autoritario: al apelar a la "objetividad" de la ciencia, a su correspondencia con la Realidad, y, quizás, a su superioridad indiscutible frente a otras tradiciones, parecen volverse a situar los valores y elementos que en definitiva condicionan su actividad a principios externos a sí mismas. Es este punto, combinado con el anterior, el que creo causa problema a, por ejemplo, Gellner (1982:186) cuando plantea que el que existan diferentes cosmovisiones, configuradas por las diferentes culturas, no niega la existencia de "verdades". Según su postura, existe, probablemente, una forma más "correcta" de acercarse a la Realidad, y afirma: 


\section{perifèria}

Número 6, Julio 2007

www. periferia. name

The problem of relativism is whether there is one and one only world, in the end; whether all the divergent visions of reality can in the end be shown to be diverse aspects of one and the same objective world, whose diversity can itself be explained in terms of the properties or laws of that world. There are some reasonably persuading, if not formally compelling, reasons for holding the belief in such unique reality.

Parte de dichas razones son, sin duda, algunos de los efectos devastadores que el relativismo llevado al extremo puede tener. ¿Cuáles son? Podemos intuir algunos a partir de lo que aparece en las críticas siguientes.

\section{Crítica 3. Si todo es falso, el relativismo es falso}

Esta crítica trata de demostrar lo autocontradictorio del relativismo en un sentido lógico: si el debate se sitúa en términos de Verdad, el relativismo sería evidentemente falso, ya que la premisa relativista sería aquella según la cual "ninguna proposición es verdadera en todos los contextos", en contraposición con el universalismo. Si esta proposición es falsa, entonces existe por lo menos una proposición que sea verdadera en todos los casos, con lo cual el relativismo es, obviamente, falso. Si su proposición es verdadera entonces existe por lo menos un contexto en el cual resulta ser falsa, ya que existe por lo menos un contexto en el cual se puede afirmar que una "proposición es verdadera en todos los contextos". Por tanto el relativismo se refuta, inevitablemente, a si mismo. Esta crítica desde la lógica es una de las más utilizadas en el debate: aparece en Gellner (1982:183), por ejemplo, cuando afirma: "there is no room for the assertion of relativism itself, in a world in wich relativism is true". Por otra parte Díaz (1991:11), la señala como “autorrefutación o falacia de la autoexcepción: proponer una generalización [...] que en principio comprende a todas las personas pero que, inconsistentemente, no se aplica a quien la enuncia". En los mismos términos, Tambiah (1990:3) afirma: "el relativismo radical es en sí mismo inconsistente pues significa que quien se define como tal no puede defender el relativismo como postura general". Siguiendo de nuevo a Ibáñez (2001:65), lo que parece suceder es que lo que se trata de demostrar y el método de demostración están intrínsecamente ligados entre sí. Naturalmente, el relativismo es falso si asume como propio lo que cuestiona para los otros y se presenta a sí mismo como portador de una Verdad absoluta. El 


\section{perifèria}

Número 6, Julio 2007

www.periferia.name

relativismo es, por definición, auto contradictorio si se le obliga a aceptar lo que cuestiona, es decir, la versión absolutista del concepto de verdad:

Protágoras no dice en ningún momento que su afirmación sea verdadera en el sentido en que lo entiende el absolutismo, es decir "verdadera para todos y en todos los contextos", sino que dice precisamente lo contrario. Dice que su propia afirmación será verdadera para unos y falsa para los otros. Y esto disuelve inmediatamente la supuesta contradicción. El relativismo es obviamente falso en el contexto absolutista [...], pero esto no vale como argumento en su contra sino que, curiosamente, constituye un argumento a su favor porque muestra, precisamente, que la verdad es relativa a la gramática que se utiliza (2001:66).

\section{Crítica 4. Entonces, ¿Todo vale?}

Continuando con lo anterior, la siguiente frase me parece sintomática de por donde puede seguir desarrollándose el debate: “Es precisamente cuando juega en el terreno de la ética [y no en el de la epistemología] cuando el relativismo está jugando en casa" (Ibáñez, 2001:58). Puede parecer sorprendente afirmar esto, cuando el otro grueso de las críticas en contra del relativismo va por este camino. Todorov (1988:3), por ejemplo, identifica esta justificación de todas las posturas con el relativismo, cuando dice que no quiere traicionar el ideal universalista, que no "todo vale". El relativismo que estamos abordando aquí no parece afirmar, como se suele argumentar, que "cualquier posición es tan buena como cualquier otra, ni mejor ni peor, y que todas son equivalentes", sino que cualquier posición es tan buena como cualquier otra en cuanto a la verdad de su fundamentación, la cual es simplemente nula para todas ellas. Esto no quiere decir que tenga que renunciar a que ciertas posiciones son mejores que otras, pero presumiblemente no bajo el criterio de su Verdad, rechazado rotundamente por el relativismo. Entonces, el relativismo radical declara abiertamente que ciertas posturas son mejores que otras y que está eventualmente dispuesto a luchar por ellas, pero declara al mismo tiempo, sin el menor rubor, que esas posturas (incluso la suya propia) carecen de fundamentación última. De ahí el problema, y la idea de que el relativismo debe ser contrarrestado "por el bien de la humanidad": "A spectre haunts human thought: relativism. If truth has many faces, then not one of them deserves trust or respect" (Gellner, 1982:181). La falta de valores universales podría justificar y consentir, 


\section{perifèria}

Número 6, Julio 2007

www. periferia. name

por ejemplo, nuevos genocidios como el perpetrado por los nazis. Para Díaz (1991:11), "nos obliga a justificar al nazismo y al nuevo imperialismo norteamericano finisecular". O, como afirma Todorov (1988:6):

El peligro [de universalizar] existe, yo lo reconozco; pero yo temo aun más el peligro opuesto, la renuncia de todo horizonte de universalidad, pues su consecuencia es el abandono de la idea de unidad de la especie humana, lo cual abre la posibilidad de decidir el exterminio de una parte de la humanidad, declarándola inferior o incluso indigna de vivir.

Es cierto (y es una de las críticas más duras) que, en última instancia, agotada la argumentación, desde el relativismo radical sólo quedarían las relaciones de poder (en términos similares a los propuestos por Foucault y otros) como mecanismos que dirimen las controversias; pero en realidad en esto no existe ninguna diferencia con el absolutismo, que también recurre a la fuerza para zanjar las diferencias con quienes no asumen las reglas de juego. En otras palabras, la creencia en un valor "universal", ni garantiza la calidad de dicho valor, ni implica una práctica coherente con él, ni exime ésta última de tener consecuencias atroces. Ambas posiciones (relativista y absolutista) son, entonces, equivalentes en este aspecto, pero existe una diferencia importante: el punto de vista absolutista implica, en muchas ocasiones, enmascarar el uso de dicho poder, legitimándose implícitamente a partir de la objetividad y la apelación a valores superiores y universales, e introduciendo, mediante esta ocultación, una violencia añadida. La cuestión es, entonces, cuál de las dos posturas sería menos "violenta". Evidentemente esto es incómodo, pero la cuestión entonces (difícil de responder) sería si puede existir una postura "no violenta" en términos de construcción de saber. Esta argumentación tiene mucho que ver con las propuestas de saber-poder que plantea Foucault, y en contra de la Verdad (con mayúscula), en tanto que "la voluntad de Verdad es directamente una voluntad de poder que pretende legislar para la eternidad" (Ibañez, 2001:57).

Por otra parte, al enmascarar las relaciones de fuerza, al apelar la "verdad" y la "esencialidad", también se camufla el hecho de que las cosas pueden modificarse articulando nuevas relaciones de fuerza. De esta forma, se oculta la posibilidad de "disolver dicha reificación [...] vinculada con la capacidad de la comprensión por parte de los actores de que las estructuras son sus propios productos, pero también 


\section{perifèria}

Número 6, Julio 2007

www. periferia.name

con la recuperación (práctica) de su control sobre ellos." (Giddens, 1987 [1967]:127., citado en González Echevarría, 2006:17). En definitiva, se hace borrosa la posibilidad de ser conscientes, quizás como mantuviera Horkheimer (1974b [1937]:61, citado en González Echevarría, 2006:14) de que los seres humanos pueden transformar lo que existe, y de que las condiciones de esa transformación se pueden dar en este momento.

\section{Crítica 5. El relativismo desactiva todo sentimiento de responsabilidad y compromiso ético-político}

La crítica anterior viene muy en relación con esta. Si se mantiene lo anterior, ¿qué sentido tiene actuar? Esto debe conducir necesariamente a la desmovilización, la pasividad y la falta de implicación. Un buen ejemplo es la crítica que Habermas realiza a Deleuze, Foucault y Lyotard (Aguilera, 2002), en la que los tacha de neoconservadores, sin una capacidad crítica y transformadora, por "no ofrecer "ninguna razón teórica [racional] para tomar una dirección social mejor que otra." Habermas propone "conservar al menos un eje seguro [porque] todo el que abandone tal enfoque [...] desecha las nociones que se han utilizado para justificar las diversas reformas de la historia de las democracias occidentales desde la Ilustración." De la misma manera, Alan Sokal, en uno de los artículos del llamado "Sokal affair"12 explicaba que una de sus motivaciones (aparte de la muy respetable crítica a lo críptico de algunos textos posmodernos) era, fundamentalmente, política:

For most of the past two centuries, the Left has been identified with science and against obscurantism; we have believed that rational thought and the fearless analysis of objective reality (both natural and social) are incisive tools for combating the mystifications promoted by the powerful -- not to mention being desirable human ends in their own right. The recent turn of many "progressive" or "leftist" [...] social scientists toward one or another form of epistemic relativism betrays this worthy heritage and undermines the already

\footnotetext{
12 En 1996, la revista Social Text publicó un artículo de Sokal titulado Transgressing the Boundaries: Toward a Transformative Hermeneutics of Quantum Gravity (Sokal, 1996a). Poco después, en la revista Lingua Franca (1996b), Sokal reveló que dicho artículo era en realidad un intento de colar (con ánimo crítico) un texto que coincidiera con las preconcepciones de los redactores, con un estilo claramente acorde con el de Social Text, pero contenidos poco menos que absurdos. Para una compilación de todos los textos ver Sokal (2007)
} 


\section{perifèria}

Número 6, Julio 2007

www.periferia.name

fragile prospects for progressive social critique. Theorizing about ' the social construction of reality" won't help us find an effective treatment for AIDS or devise strategies for preventing global warming. Nor can we combat false ideas in history, sociology, economics and politics if we reject the notions of truth and falsity. (Sokal, 1996b: 4-5)

No hay duda de que una "teorización sobre la construcción social de la realidad", como sustitutiva de la construcción de conocimiento comprometido y crítico con la realidad social en la que se produce, puede implicar falta de compromiso ético y político. Pero la creencia o el apoyo en un absoluto, o en una idea universal, por sí sola, tampoco garantiza un compromiso de actuación ${ }^{13}$. Sokal está presentando, por tanto, una cuestión que va más allá de la fundamentación a partir del análisis de una realidad objetiva. De hecho, la inercia y la desmovilización también son posibles cuando se cree que la Verdad y los Valores están ahí de todas formas y seguirán ahí se haga lo que se haga (o bien cuando, por ser considerados valores superiores, se cree en ellos ciegamente). Pero si resulta que las certezas y valores son relativos a las prácticas que los establecen, y si sólo pueden ser apoyados por dichas prácticas, no hay otra forma de sustentarlos más que la que consiste en activarlas permanentemente. Evidentemente, esto también tiene unas implicaciones profundas para las ciencias sociales, ya que incide, una vez más, en la no-neutralidad ética y política. Si nuestras prácticas no sólo tienen efectos, sino que adquieren un papel definitorio de nuestros argumentos, es imposible no ser consciente de que uno está ejerciendo constantemente una toma de partido, lo cual, al menos en teoría, debería abocarnos a un mayor compromiso con dichas prácticas y sus efectos.

\section{Crítica 6. Entonces, ¿no se pueden emitir juicios morales?}

Si ninguna tradición presenta mayor fundamento que cualquier otra, el relativista debería respetarlas todas por igual, tanto si, pongamos por caso, abogan por el totalitarismo como si propugnan la libertad. Sobre esta cuestión existen multitud de

\footnotetext{
13 Rorty, por ejemplo, plantea que “"'los 'posmodernos' están en lo cierto filosóficamente, pero son políticamente insensatos, mientas que los 'ortodoxos' están filosóficamente equivocados y son políticamente peligrosos" (Rorty 1999: 88, citado en Aguilera, 2002)
} 


\section{perifèria}

Número 6, Julio 2007

www.periferia.name

ejemplos, que no es necesario enumerar, y que son recurrentes en el debate. La posición más extrema posible del relativista normativo, explicada de una forma simplista, es que nadie debería juzgar nunca a otras personas con valores sustancialmente diferentes ni intentar que se adecuen a los propios valores. Lo que queda es una realidad moral bastante embarullada e inmune a las soluciones simples, que afecta, aun más si cabe que las anteriores, de lleno a la antropología. Jarvie (1983), por ejemplo, afirma que si "todos los juicios son relativos a un estándar u otro, y los estándares derivan de las culturas, quedamos desarmados, sin posibilidad de entrar en interacción comunicativa, de criticar interculturalmente, intersubculturalmente, de criticar, en suma" (Geertz, 1984:266, Citado en González Echevarría, 2006: 35)

Dicho relativismo implicaría, por tanto, la imposibilidad de emitir valoraciones o críticas a otras posturas, por el simple hecho de ser relativas. Sin embargo que las tradiciones no tengan, en el fondo, fundamentación en un sentido de verdad (de que esta sea nula para todos los casos) no quiere decir que haya que tratarlas a todas por igual, sino que su mayor o menor "respetabilidad" es relativa a los valores que se articulan para enjuiciarlas, y esos valores no tienen otra defensa que nuestra capacidad para defenderlos (Ibáñez, 2001:62). En otras palabras, posibilidad de valorar y criticar, sí, pero no apoyada en supuestos universales que trascienden nuestras propias prácticas, lo que debería, en principio, empujar a la argumentación. Digo “debería” porque la argumentación es también una opción, y por tanto cuesta responder a una cuestión muy simple: es fácil deplorar o argumentar en contra de una práctica que, según tus valores relativos, enjuicias como negativa. Pero ¿si tuviéramos el poder para modificarla, impondríamos dicho cambio? Quizás sólo se podría responder a través de un argumento ya presentado: el absolutismo, el que afirma que existen valores universales, también los impone, y además lo hace usando un criterio de Verdad, que añade un plus de violencia. Nos encontramos, de nuevo, con un interrogante difícil de responder; con la incomodidad de optar, quizás, por la opción "menos mala".

En ocasiones, se tiende a considerar el relativismo como postura que, por si misma, produce espacios de libertad. Es difícil, entonces, pensarla como poder dominante 


\section{perifèria}

Número 6, Julio 2007

www.periferia.name

con capacidad para imponer. Porque el relativismo radical sólo afirma que nuestros valores sólo pueden sustentarse en nuestras prácticas, y, por tanto, no tiene porqué predisponer cuales son dichas prácticas. Si lo hiciera, se estaría situando en un espacio que no es el suyo, en el que ciertas pautas acaban siendo, de nuevo, universales y trascendentes, cuando lo realmente importante es la crítica a la que el relativismo obliga, que:

(...) cuestiona todos los principios de autoridad y cree que es posible hacer descansar los valores, su legitimación, su defensa, en algo tan frágil como son las "prácticas de libertad", y en algo tan aparentemente inconsistente y tenue como puedan ser unos criterios que no disponen de otra fuente de legitimación que nuestras propias prácticas y nuestras propias decisiones. Simplemente humanas. (I báñez, 2001:71)

De esta forma, el relativismo radical sólo se podría amparar en la convicción (relativa) de que sus prácticas no van a generar opresión sino libertad. Lo cual es, con toda seguridad, una solución incompleta, pero, de nuevo, quizás toda la que tenemos y podemos tener.

\section{Crítica 7: El relativismo y la posibilidad de una aproximación científica}

Podría dar la impresión de que todo lo anterior hace imposible una aproximación científica para la disciplina antropológica. Efectivamente, es así, al menos para una cierta forma de plantear dicha aproximación: desde luego, para aquella basada en la búsqueda de unos supuestos universales invariantes, empeñada en descubrir y desentrañar la verdadera esencia, oculta e inmutable, de los hechos socioculturales; incluso para aquella que admite el multiperspectivismo y el papel del investigador en la interpretación (pero no en la atribución de modalidades de existencia) de un cierto objeto de estudio. Y también, obviamente, para aquella que plantea que la construcción (acumulativa) de conocimiento, la comparación y discusión entre versiones, únicamente puede darse desde la asunción de una realidad externa, verdadera y última. Cuando Gellner, por ejemplo, afirma "science needs one world" (1982:200), propone también, de una forma aun más clara: 


\section{perifèria}

Número 6, Julio 2007

www. periferia. name

If like conditions did not produce like effects, then the experimental accumulation of knowledge would have no point and would not be feasible. Only theories built on the assumption of symmetry and orderliness can be negotiated and applied. (1982: 189)

Sin embargo, y siguiendo con la argumentación, las teorías, construidas en base a la verdad (con minúsculas) pueden tener aplicación, y, de hecho puede entenderse que deben estar constituidas por ella, que son inseparables de la propia aplicación. Respecto a la negociación, me remito a las críticas anteriores, y, particularmente, a algunas de las aportaciones de Feyerabend: bloquear toda argumentación, poner fin a todo diálogo no es patrimonio del relativismo, o al menos no es un efecto inmediato del mismo. El hecho de recurrir a absolutos justifica con mucha más facilidad el llegar a un punto en el que ya no hay discusión posible, en el que se apela a una verdad fuera de la propia argumentación. ¿Se sitúa entonces el relativismo (al inhibir, en los términos de Gellner, la asunción de simetría) fuera del ámbito de lo científico? Utilizando (por última vez) el texto de Ibáñez (2001:85), una posible respuesta es:

Al contrario, resulta que lo que pretende el relativista es que no haya nada que pueda situarse fuera de lo investigable, de lo que debe ser escrutado, de lo que debe ser problematizado y cuestionado. Nada, ni siquiera la razón, ni siquiera la ciencia. Por lo tanto, se podría decir que el relativista es el más fiel exponente del ethos de la ciencia.

\section{Apuntes finales: el relativismo y una antropología científica, crítica y basada en la comparación.}

En principio no parece existir, por tanto, la necesidad de renunciar globalmente a la posibilidad de hacer una antropología científica, sino, quizás, de reinterpretarla teniendo en cuenta algunos de los elementos que implican los temas antes tratados. Recapitulando lo expuesto, la intersección (que por otra parte ya existe) de una cierta posición relativista con la práctica antropológica parece tener más ventajas que inconvenientes, muchas de las cuales ya he mencionado: obliga, -si bien es cierto que ello puede formularse también desde otros posicionamientos- , a una reflexión constante sobre los conceptos que utilizamos y las prácticas que ponemos en juego; a admitir que todas ellas tienen efectos; a visibilizar dichos efectos de poder en la construcción de conocimiento; a la argumentación y al 


\section{perifèria}

Número 6, Julio 2007

www.periferia.name

debate, más que a la imposición en términos de Verdad. En concreto, para el relativismo cultural (el de la corriente culturalista norteamericana), ciertas ventajas también son evidentes y coherentes con lo anterior. Señalando lo planteado por Díaz (1991:4), dicho relativismo, incorporado tácitamente o no a la enseñanza y formación iniciales del antropólogo,

(...) previno a la antropología de realizar generalizaciones fáciles y contundentes; introdujo [...] escepticismo en la construcción de la teoría antropológica; resaltó el fuerte carácter etnocéntrico [...] implícito en la teoría evolucionista; condenó el vínculo existente entre colonialismo, etnocidio y antropología; y, en fin, subrayó el hecho elemental de que la antropología, como cualquier otra disciplina científica, es una actividad social y humana, un proceso de producción cultural cuyos saberes y actividades son producidos por comunidades científicas con sus propios intereses, desasosiegos y reglas de poder.

La cuestión es, entonces, tal y como plantea González Echevarría (2003), cuales son los límites para que la aplicación de dicho relativismo permitan una cierta antropología (si se quiere, científica, crítica, que permita la comparación). Y este relativismo tendría que ver, al menos, con tres ámbitos (González Echevarría, 2003:403-406): un precepto metodológico antietnocéntrico, la cuestión de la comparabilidad entre culturas o formas de conocimiento y una dimensión ética. Intentando ponerlas en coherencia con lo presentado anteriormente, veamos cual puede ser el encaje de cada una con los presupuestos relativistas desarrollados aquí.

En primer lugar, parece que existe una coincidencia total en cuanto al precepto metodológico antietnocéntrico (un relativismo antietnocéntrico), en cuanto a la insistencia a la hora de prescindir hasta donde podamos de las preconcepciones culturales. Eliminar la posibilidad, tal y como se ha planteado en las críticas anteriores, de justificar la construcción de conocimiento y el uso de unos determinados conceptos a partir de una supuesta realidad externa al observador, debería implicar la necesidad de contrastación (si se quiere, deconstrucción) de dichas preconcepciones; o al menos, debería hacerlas más visibles.

En cuanto a la comparabilidad, cuando, en apartados anteriores, mencionaba los tipos de relativismos, hablaba, en último lugar, del relativismo cognoscitivo, que 


\section{perifèria}

Número 6, Julio 2007

www.periferia. name

refuerza el relativismo epistemológico", al tratar "como elementos de culturas incomparables conocimientos que se desarrollan en el seno de nuestra tradición cultural" (González Echevarría, 2003:402). Coincido plenamente con que "al final la comprensión y la interpretación -necesarias para que sea posible algún conocimiento antropológico- marcarían el límite del relativismo cultural." (González Echevarría, 2006:36). De no ser así, nos aproximaríamos a la ya mencionada inconmensurabilidad, tanto para la comparación entre elementos culturales como para la contrastación de teorías sobre dichos elementos. En ese sentido, Geertz (1999) considera la comunicación entre las diferentes culturas, no ya como posible, sin incluso como necesaria (a lo que quizás habría que añadir inevitable). Pero hay algunas cuestiones aquí que cabe tener en cuenta: la primera es, precisamente que a pesar de que Geertz es considerado, en ocasiones, como un autor defensor del relativismo, él prefiere hablar de sus argumentos como anti-antirelativistas. De hecho, para él, el gran problema del relativismo es que sus características se configuran en oposición al discurso anti relativista, cuando éste afirma que el relativismo niega la comparación intercultural y enfatiza la sociedad cerrada. Quizás, como en la tercera crítica, que intentaba apuntar lo autocontradictorio del relativismo en el plano formal, este resulte falso si asumiera para sí mismo lo que cuestiona para otros: en otras palabras, si afirmara acríticamente que la comunicación y comparación son universales, frente a las posibles concepciones cotidianas y relacionales de estos términos. La cuestión es, como en apartados anteriores, de qué tipo de relativismo se está poniendo en juego: de si dicha comparación y comunicación se realiza sobre la convicción en una realidad externa, inmutable y por descubrir, o sobre la contrastación y el análisis de las condiciones de construcción de los argumentos, prácticas y efectos. Por tanto, la negación de las concepciones "absolutistas" quizás no implica el abandono de cierta concepción de universales, si se quiere, en el sentido de "universos de significado" de los Wittgenstenianos que, como mantuvo Giddens para la comprensión, "es la misma condición ontológica de la vida humana en sociedad como tal; [...] la comprensión

${ }^{14}$ Que implicaría la imposibilidad de contrastar el acceso a la realidad de las diferentes "visiones del mundo". 


\section{perifèria}

Número 6, Julio 2007

www.periferia. name

de uno mismo está conectada integralmente con la comprensión de los otros" (1987:21, citado en Díaz, 1991:5). En ese sentido, quizás seguiría siendo posible, a pesar de una crítica a los "absolutismos", afirmar que "para cualquier comprensión [y comparación] es necesaria alguna forma de traducción. Es necesario tender cabezas de puente. Y hacerlo exige algún tipo de universalidad" (González Echevarría, 2003:403). Más que centrarse en la estricta universalidad o no de dicha posibilidad de comparación, de dicha comunicación, cabría entonces centrarse en elaborar, desde la propia responsabilidad, una fundamentación que la permita. $Y$ siguiendo la argumentación presentada en el texto de González Echevarría (2003:406), el relativismo mantenido por Ibañez no está tan lejos - al menos, en sus efectos- de los términos en los que se formula el antirrelativismo cognoscitivo, que trata en cada caso "de no ser dogmático, de trazar la génesis histórica de sus presupuestos, de ser, en definitiva, crítico, contradictoriamente relativista". Antirrelativismo cognoscitivo (o teórico), al que quizás habría que buscar otro nombre, porque, tal y como se ha presentado en apartados anteriores, no parece que la propuesta "relativista radical" niegue o inhiba la posibilidad de comparación entre teorías científicas. En todo caso (y ese es un debate que no me atrevo a introducir aquí), la cuestión es en qué términos (o en que campo de juego) se produce dicha comparación: el cómo resolver su complejidad al renunciar, como apunta Díaz (1991:3) a un "único metalenguaje por medio del cual evaluar unívocamente paradigmas alternativos y en competencia". Digo que no profundizaré más en el debate, aunque una de sus claves pueda ser, precisamente, la calidad, la rigurosidad en el diseño, la recogida de datos y la contrastación: "una cosa es que el conocimiento sea relativo al resto de la cultura y otra que aceptemos cualquier forma de conocimiento. Desde mis principios valorativos, confío en un conocimiento que se caracterice por el énfasis en la puesta a prueba, en la crítica" (González Echevarría, 2003:406).

Finalmente, y en lo referente a su dimensión ética, la posibilidad de crítica constituiría un nuevo límite de dicho relativismo cultural. Ya he abordado esta cuestión en la cuarta, quinta y sexta críticas, y por tanto no la retomaré aquí. Baste decir que, por paradójico que parezca, un "antirelativismo ético" no parece 


\section{perifèria}

Número 6, Julio 2007

www.periferia.name

incompatible con el "relativismo radical", tal y como se ha formulado. Un relativismo ético ingenuo sí dejaría intactas críticas como las de Sebreli (1992), García Canclini (1988) y Jarvie (1983) ${ }^{15}$, pero el expuesto aquí parece enfrentarlos y solucionarlos de otra manera, sin recurrir a la universalidad de ciertos valores. Sin embargo, y aunque todo pueda ser relativizable en los términos anteriores, cabe hacer explícito que dicha relatividad se basa en los propios valores, relativos, eso sí. De nuevo, la cuestión es respecto a qué se relativiza, y nadie niega que podamos relativizar respecto a nuestros propios "universales", pero teniendo en cuenta que son los nuestros, que no son verdades últimas. En otras palabras, que yo crea en la justicia social, en la solidaridad, en la igualdad, en el cuestionamiento de la autoridad, etc. no convierte mis creencias en verdades universales, ni me empuja a justificarlas con ideas externas al terreno de lo social, de lo humano. De hecho, sólo las convierte en valores que yo considero extensibles o aplicables de una forma amplia, pero que sólo puedo basar en mis prácticas. $Y$ esto tampoco incapacita para ejercer críticas desde los propios posicionamientos, aunque obliga a argumentarlos y fundamentarlos convenientemente, abriendo el camino a la necesidad de entender los de otros y, si es el caso, a cambiar los propios desde dicha comprensión. Como afirma González Echevarría:

Comprenderlo todo no es perdonarlo todo, ni frenar el cambio colocando en una vitrina la diversidad cultural. [...] Nuestros juicios no son objetivos, son nuestros, y nada nos impide hacerlos, [...] pero entender añade racionalidad a mis juicios y conocer otras maneras de ser humano puede modificarlos. (González Echevarría, 2003:404)

O como plantea San Román, en una cita que tiene además que ver con varias de las cuestiones planteadas aquí - la emisión de valoraciones morales, la coherencia en las prácticas y la implicación en la defensa de unos determinados principios-:

El anteponer el respeto cultural a cualquier otro tipo de consideraciones, simplemente confieso que no es mi opción. A partir de aquí, acepto que utilizo referentes. No me apoyo en ningún supuesto de universalidad porque es una opción, no una teoría. Porque no es necesaria ninguna teoría para mantener un proyecto universal personal-cultural. Más vale, por el contrario, reconocer que no

\footnotetext{
${ }^{15}$ Los tres citados en González Echevarría (2003:404)
} 


\section{perifèria}

Número 6, Julio 2007

www. periferia.name

es universal y dar buenas razones para afirmar nuestra disposición a defenderlo. Y a cómo hacerlo sin contradecirse. (San Román, 1996: 122)

\section{Bibliografía}

\section{Citada}

Aguilera, R. (2002). El problema del etnocentrismo en el debate antropológico entre Clifford Geertz, Richard Rorty y Lévi-Strauss. [En línea] Gazeta de antropología, 18. Texto 18-11. Página web de la versión electrónica de la revista $<$ http://www.ugr.es/ p pwlac/G18 11Rafael_Aguilera_Portales.html\#1> [Consulta, 15 de Marzo de 2007]

Asimov, I. (2003 [1986]). Fundación y Tierra. Barcelona, Debolsillo

Cañizares, A. (2007). Estamos por la vida, pero no por el relativismo. [En línea] Web de la Conferencia Episcopal Española. $<$ http://www. conferenciaepiscopal.es/obispos/autores/canizaresllovera/04. htm> [Consulta, 30 de Marzo de 2007]

Díaz, R. (1991). Los hacedores de mapas: antropología y epistemología. Una introducción. [En línea] Alteridades 1 (1), 3-12. Página web de la versión electrónica de la revista <http://148.206.53.230/revistasuam/alteridades/include/getdoc. php? rev=alteridad es\&id=299\&article=201\&mode=pdf $>\quad$ [Consulta, 15 de Febrero de 2007] .

Feyerabend, P. (1974). Contra el método. Barcelona, Ariel.

Foster, L. (1988). Strong Relativism Revisited. Philosophy and Phenomenological Research, 49 (1), Septiembre, 145-150.

Geertz, C. (1999). Los usos de la diversidad. Barcelona: Paidós ICE / UAB.

Gellner, E. (1982) Relativism and Universals. En: Hollis, M. y Lukes, S., eds., (1982) Rationality and Relativism, Oxford, Blackwell.

González Echevarría, A. (2003). “Tesis epistemológicas. Las paradojas del relativismo". En: González Echevarría, A. (2003) Crítica de la singularidad Cultural. Barcelona, Ed. Anthropos / Universidad Autónoma Metropolitana, México D.F., 400416.

I báñez, T. (2001). Municiones para disidentes. Realidad-verdad-política. Barcelona, Gedisa.

Rouco, A. (2006). La cuestión ética, ante el futuro del Estado democrático. [En línea] Agencia de noticias Zenit. $<$ http://www.zenit.org/spanish/visualizza.phtml?sid=91493> $\quad$ [Consulta, 10 de Febrero de 2007].

San Román, T. (1996). Los muros de la separación. Ensayos sobre alterofobia y filantropía. Tecnos-Servei de publicacións UAB, Madrid-Bellaterra.

Sokal, A. (1996a). Transgressing the Boundaries: Toward a Transformative 


\section{perifèria}

Número 6, Julio 2007

www.periferia.name

Hermeneutics of Quantum Gravity. [En línea] Social Text, 46/47, 217-252. $<$ http://www. physics.nyu.edu/faculty/sokal/transgress v2 noafterword.pdf> [Consulta, 10 de Marzo de 2007].

Sokal, A. (1996b) A Physicist Experiments with Cultural Studies. [En línea] Lingua Franca, Mayo/J unio 1996, 62-64. <http://www. physics.nyu.edu/faculty/sokal/lingua franca_v4.pdf> [Consulta, 10 de Marzo de 2007].

Sokal, A. (2007) Alan Sokal articles on the "social text" affair. [En línea] Página web personal en el Department of Physics de la New York University. <http://www.physics.nyu.edu/faculty/sokal/index.html> [Consulta, 10 de Marzo de 2007].

Tambiah, SJ . (1990) Rationality, relativism, the translation and commensurability of cultures. En: Tambiah, SJ. (1990) Magic, Science, Religion, and the Scope of Rationality, Cambridge University Press.

Todorov, T. (1988) “Le projet universaliste”. Anthropologie et Sociétés 12 (1). Traducción de Stolcke, V. (1997).

\section{Referida}

Bernstein, RJ. (1991) The new constellation. The ethical-political horizons of modernity / postmodernity, Cambridge, Polity press.

García Canclini, N. (1988) La crisis teórica en la investigación sobre cultura popular. Teoría e Investigación en la Antropología Social, México: CIESAS / UAM-I.

Geertz, C. (1984) Anti Anti-relativism. American Anthropologist, 86.

Giddens, A. (1987 [1967]) Las nuevas reglas del método sociológico. Una crítica positiva de la sociología interpretativa. Buenos Aires. Amorrortu.

Goodman, N. (1990) Maneras de hacer mundos, Madrid, Visor.

Horkheimer (1974 [1968]) Théorie traditionelle et théorie critique. París, Gallimard.

Jarvie, IC. (1983 [1964]) Explaining Cargo Cults. En: Wilson, BR., ed. (1970) Rationality, Oxford,Blackwell, 50-61.

Kaplan, D. y Manners, RA. (1975) Antropología: viejos temas y nuevas orientaciones. En: Llobera, J., ed., (1975) La antropología como ciencia. Barcelona, Anagrama, 55-76.

Morrow, RA. y Brown, DD. (1994) Critical Theory and Methodology, Londres, Sage publications.

Rorty, R. (1996) Objetividad, relativismo y verdad, Paidos, Barcelona.

Sebreli, J.J. (2000) El asedio a la modernidad. Crítica del relativismo cultural. Barcelona, Ariel.

Spiro, M. (1984) Cultural relativism and the future of Antrhopolology. Cultural Anthropology, 1:259-285. 